\title{
O PROEJA E O PROCESSO DE IMPLANTAÇÃO PEDAGÓGICA NO INSTITUTO FEDERAL DE EDUCAÇÃO, CIÊNCIA E TECNOLOGIA DO
}

\section{MARANHÃO}

\author{
Suzana Andréia Santos Coutinho 19 \\ Lélia Cristina Silveira de Moraes 20
}

\section{RESUMO}

Este artigo aborda a implantação do PROEJA - Programa Nacional de Integração da Educação Profissional com a Educação Básica na Modalidade de Educação de Jovens e Adultos, na sua condição de política educacional no contexto do Instituto Federal de Educação, Ciência e Tecnologia do Maranhão - IFMA, Campus Maracanã. Para a realização deste estudo, utilizamos o Documento Base Nacional do PROEJA, bem como autores que tratam da EJA e a proposta pedagógica do IFMA. A pesquisa em análise é de cunho qualitativo, abrangeu as coordenadoras pedagógicas, uma geral e outra do curso técnico em Agropecuária-PROEJA e professores, com o objetivo de compreendermos as percepções destes sujeitos em relação ao processo de implantação do programa, na sua dimensão pedagógica. O PROEJA é um programa educacional que se encontra fundamentado nos princípios educativos da Educação de Jovens e Adultos e apresenta em sua proposta curricular a integração entre trabalho, educação, ciência e tecnologia, com o objetivo de contribuir para o enriquecimento científico, cultural, político e profissional do aluno. Fundamentamo-nos em BRASIL (2005), BRASIL (2007), FREIRE (1996), IFMA (2010), PAIVA (1973), PAIVA (1987), dentre outros. O estudo nos revelou que a implantação do PROEJA no contexto do IFMA Campus Maracanã foi de extrema importância por possibilitar aos jovens e adultos uma formação geral aliada à formação profissional, além do compromisso e responsabilidade que a instituição tem com o programa e sua expansão, apesar da fragilidade demonstrada pela maioria dos sujeitos pesquisados em relação a essa compreensão.

Palavras-chave: PROEJA. Formação Profissional. Formação Geral.

\footnotetext{
19 Graduanda do Curso de Pedagogia na Universidade Federal do Maranhão - UFMA. Email: suzanasantoscoutinho@outlook.com

20 Doutora em Educação Brasileira pela Universidade Federal do Ceará. Docente da Universidade Federal do Maranhão. E-mail: lelia.silveira@ufma.br
} 


\title{
THE PROEJA AND THE PROCESS OF PEDAGOGICAL IMPLANTATION AT THE FEDERAL INSTITUTE OF EDUCATION, SCIENCE AND TECHNOLOGY OF MARANHÃO
}

\begin{abstract}
This article deals with the implementation of PROEJA - National Program for the Integration of Professional Education with Basic Education in the Youth and Adult Education Modality, as an educational policy in the context of the Federal Institute of Education, Science and Technology of Maranhão-IFMA, Campus Maracanã. In order to carry out this study, we used the PROEJA National Basis Document, as well as authors dealing with the EJA and the pedagogical proposal of IFMA. The research under analysis is qualitative, covering the pedagogical coordinators, a general and another one of the technical course in Agropecuária-PROEJA and teachers, with the aim of understanding the perceptions of these subjects concerning the process of implementation of the program, in its pedagogical dimension. PROEJA is an educational program that is based on the educational principles of Youth and Adult Education and presents in its curricular proposal the integration between work, education, science and technology, with the objective of contributing to scientific, cultural and political and professional enrichment of the student. We are based on BRASIL (2005), BRASIL (2007), FREIRE (1996), IFMA (2010), PAIVA (1973), PAIVA (1987), among others. The study revealed that the implementation of PROEJA in the context of IFMA - Campus Maracanã was extremely important because it enabled young people and adults to have general education in alliance with professional education, as well as the commitment and responsibility that the institution has with the program and its expansion, despite the fragility shown by most of the subjects surveyed in relation to this understanding.
\end{abstract}

Keywords: PROEJA. Professional Education. General Formation.

\section{INTRODUÇÃO}

Neste artigo, abordamos a implantação do PROEJA - Programa Nacional de Integração da Educação Profissional com a Educação Básica na Modalidade de Educação de Jovens e Adultos, no contexto do Instituto Federal do Maranhão, Campus Maracanã, na condição de política educacional que integra formação geral aliada à formação profissional, levando em consideração os aspectos organizacionais e pedagógicos estabelecido pelo Documento Base Nacional para o Ensino Médio.

A sociedade tem vivenciado na atualidade momentos de significativas transformações políticas, econômicas e sociais, o que leva o 
país a se desenvolver de acordo com tais mudanças. Essas transformações acarretam mudanças significativas na educação e no perfil do trabalhador que a escola prepara para inseri-lo no mercado de trabalho. Diante disso, o campo educacional passa a ser alvo dessa nova concepção de sociedade, ficando sujeito a uma situação que foge aos princípios, leis e regras que fundamentam a educação em si e que passam a ser questionados e colocados de lado sendo substituídos por uma concepção capitalista que envolve a sociedade como um todo.

É a partir desse contexto de transformação da sociedade e consequentemente da escola é que buscamos subsídios para compreender - PROEJA dentro dessa conjuntura, por se apresentar como uma política educacional sustentada por uma nova concepção de educação pautada na integração da elevação da escolaridade aliada à qualificação profissional.

Portanto, para uma melhor compreensão e apreensão da discussão em pauta, organizamos o artigo da seguinte forma: Discutimos a Educação de Jovens e Adultos no Brasil a partir dos anos 1990, refletindo sobre o desenvolvimento de políticas educacionais para esse público. Em seguida, tratamos sobre a política do PROEJA, objeto deste estudo. Na sequência, analisamos a Proposta Pedagógica do PROEJA no contexto do IFMA, Campus Maracanã, situando a percepção dos sujeitos envolvidos na implantação do PROEJA no contexto do Instituto Federal do Maranhão, Campus Maracanã. E por fim, apresentamos as considerações finais, que retoma a discussão apresentada com o intuito de colaborar com o conhecimento e assim encontrar alternativas para melhor desenvolver a temática abordada. 


\section{EDUCAÇÃO DE JOVENS E ADULTOS NO BRASIL A PARTIR DOS ANOS 1990: algumas considerações}

A EJA, durante muitos anos no Brasil, teve seu foco centralizado no campo da alfabetização de jovens e adultos excluídos da escola por diversos motivos, o que nos leva a pensar alternativas para amenizar essa problemática social que envolve a vida educacional de uma significativa parcela da sociedade.

A trajetória histórica dessa modalidade era vista como uma educação compensatória com a finalidade de acelerar os estudos dos alunos que não frequentaram a escola no tempo considerado regular. Contudo, as lutas sociais que se intensificaram nos anos 1990 na busca de conquistas constitucionais para perenidade de políticas públicas para a modalidade EJA e o reconhecimento da importância dessa modalidade pela Unesco, acarretaram discussões sobre o assunto e a mobilização nacional com a organização dos fóruns estaduais por todo o país, o primeiro deles acontecendo no Rio de Janeiro em 1996. Ainda nesse período, o Governo Federal criou em 1996 o Programa de Alfabetização Solidaria (PAS), que envolveu parcerias com universidades, empresas e administrações municipais. O PAS teve uma função assistencialista e não educacional de fato, pois com o tema de "Adote um analfabeto" deixou clara a finalidade desse programa, omitindo neste caso, que a educação é um direito e um dever do Estado.

Foi nesse momento que o Brasil começou a ter participação ativa na Confiteia (V Conferência Internacional de Educação de Adultos), que aconteceu em 1997 com a participação das ideias de Paulo Freire, que reafirma a importância da Educação de Jovens e Adultos como direito e não como assistencialismo como vinha sendo tratada.

Mas foi entre 2003-2010 que a educação brasileira apresentou, de fato, mudanças significativas, principalmente no que se refere à EJA, com a gestão do presidente Luiz Inácio Lula da Silva. Essas mudanças aconteceram 
por meio da presença marcante da elaboração de várias políticas educacionais voltadas a essa modalidade de ensino, no sentido de possibilitar aos jovens e adultos uma oportunidade de obter uma educação geral integrada à educação profissional. Em 2004 foi criada a Secretaria de Educação Continuada, Alfabetização e Diversidade, que passa a reunir temas de educação de jovens e adultos, educação do campo, educação indígena, educação ambiental e diversidade étnico-racial e cria políticas públicas destinadas a esses segmentos que foram excluídos durante muitos anos do contexto educacional do país.

Dessa forma, podemos salientar que a gestão governamental do presidente Lula foi a que mais se voltou para o segmento dos menos abastados da sociedade, beneficiando-os por meio de políticas educacionais. Tivemos a inclusão da EJA no Fundo de Desenvolvimento da Educação Básica (Fundeb) em 2007, embora a assistência oferecida a ela tenha sido mínima. O financiamento garantiu certo reconhecimento no sentido de que abriu portas para sua inclusão em outros programas/recursos garantidos para esse nível de educação.

Outras ações pontuais foram desencadeadas em prol da EJA como: o Programa Brasil Alfabetizado (PBA), o Programa Nacional de Inclusão de Jovens: escolarização, qualificação profissional e ação comunitária (PROJOVEM) e o Programa Nacional de Integração da Educação Profissional com a Educação Básica na Modalidade de Educação de Jovens e Adultos (PROEJA).

O PBA foi realizado pela Secretaria Extraordinária de Erradicação do Analfabetismo, criado pela Coordenação de Educação de Jovens e Adultos do MEC. Tinha como meta alfabetizar uma significativa parcela de jovens e adultos e capacitar alfabetizadores para trabalharem no programa, por meio de convênios assinados entre as esferas estaduais, municipais e instituições organizadas da sociedade civil.

Já O PROJOVEM foi implantado em 2005, vinculado à Secretaria Nacional de Juventude (SNJ). Integrou ações que objetivaram a adequação 
de uma Política Nacional de Juventude, destinada à inclusão de jovens de 18 a 24 anos, com escolaridade superior à $4^{a}$ série que não concluíram o ensino fundamental e não possuíam vínculos formais de trabalho. A meta era a integração entre a elevação da escolaridade (conclusão do ensino fundamental), a formação inicial ligada à qualificação profissional e a ação comunitária. Dessa forma, O PROJOVEM apresentou-se como uma política pública de caráter educacional, estando vigente até os dias de hoje, contribuindo para a elevação da escolaridade e inserção do jovem no mercado de trabalho.

Outro programa direcionado ao segmento juvenil foi o PROEJA criado pelo governo federal, por meio do Decreto $n^{\circ} 5.478$, que vigorou por pouco tempo, sendo substituído em 2006 pelo Decreto n 5.840, já citado anteriormente.

Portanto, os anos 2000 representam um momento de conquistas para a modalidade de Educação de Jovens e Adultos, principalmente com a gestão do presidente Lula. Diversas foram as políticas educacionais em prol do atendimento à EJA, desde quando passou a ganhar um espaço significativo com a promulgação da LDB 9394/96 até o FUNDEB. Muito ainda há de se fazer pela EJA, vários são os problemas encontrados para desenvolver suas ações, porém muito já foi feito. Cabe, assim, repensarmos sobre as concepções e encontrarmos soluções adequadas para uma educação pública de qualidade em todas as suas modalidades, sendo considerada direito de todo cidadão brasileiro.

\section{SITUANDO A POLÍTICA DO PROEJA: algumas concepções}

O PROEJA é uma política educacional que pauta-se nos princípios educativos da modalidade da Educação de Jovens e Adultos. A EJA é uma modalidade de ensino que passou por grandes transformações, que culminaram em problemas de cunho histórico, social e cultural, que configuram o cenário atual das políticas educacionais destinadas aos jovens 
e adultos, na tentativa de fomentar uma organização pedagógica significativa para a construção de uma realidade escolar sólida.

Devido a esses problemas e à busca incessante de medidas reparadoras em prol da EJA é que o Governo Federal criou o PROEJA (2005), começando com a formação inicial e continuada de trabalhadores (PROEJA FIC) seguido do PROEJA Técnico, de nível médio. Posteriormente, ocorreram modificações e foi ampliada essa oferta com a inclusão e a expansão das instituições proponentes (estaduais, municipais e entidades privadas nacionais de serviço social), com o intuito de desenvolver 0 processo de formação profissional.

O PROEJA tem como base fundamental a integração entre ciência, trabalho, técnica, tecnologia, humanismo e cultura geral, com o objetivo de colaborar com a formação dos cidadãos, pautada em princípios científicos, culturais, políticos e profissionais para o pleno exercício da cidadania, conforme orienta a sua proposta curricular.

Outro ponto que cabe destacar nessa discussão se refere ao PROEJA como proposta pedagógica que denota a intenção de ser uma política pública pautada em ações baseadas em princípios epistemológicos que atendam às necessidades educacionais da EJA, que respeitem os aspectos sociais, econômicos, culturais, intelectuais e emocionais dos jovens e adultos que se encontram em processo de aprendizagem e que proporcionem uma formação profissional que não seja direcionada somente para a inserção dessa clientela no mercado de trabalho, mas que, além de tudo, seja norteada por uma formação humana, considerando

[...] a formação humana, no seu sentido lato, com acesso ao universo de saberes e conhecimentos científicos e tecnológicos produzidos historicamente pela /humanidade, integrada a uma formação profissional que permita compreender 0 mundo, compreender-se no mundo e nele atuar na busca de melhoria das próprias condições de vida e da construção de uma sociedade socialmente justa. A perspectiva precisa ser, portanto, de formação na vida e para a vida e não apenas de qualificação do mercado ou para ele. Por esse entendimento, não se pode subsumir a cidadania à inclusão no "mercado de trabalho", mas assumir a formação do 
cidadão que produz, pelo trabalho, a si e o mundo (BRASIL, 2007, p. 13).

Como podemos observar, a política do PROEJA visa a uma formação integrada do cidadão, a qual consiste não somente na absorção de conhecimentos científicos, profissionais, mas em um conhecimento para a vida, para a sua construção pessoal como ser social que se transforma e transforma a sociedade em que se encontra inserido.

É interessante ressaltarmos, em conformidade com a proposta geral do Programa, três funções importantes para essa modalidade de ensino: as funções reparadora, equalizadora e qualificadora. Cada função dessas tem uma finalidade bem clara e importante para a EJA: a função reparadora é aquele que tem como foco o ingresso desse jovem e adulto no ciclo dos direitos civis, com todos os seus direitos garantidos, como uma instituição educacional de qualidade, ou seja, ter acesso aos bens reais e sociais importantes para a formação do indivíduo e com isso o seu pleno exercício da cidadania; a função equalizadora como o próprio nome já confirma é a que oferta oportunidades àqueles que foram desfavorecidos do acesso e permanência na escola e, por fim a função qualificadora primordial dentro do contexto da educação de jovens e adultos trabalhadores, apresentando um caráter permanente.

No que diz respeito às concepções adotadas pelo programa em seu documento base (2007) ressaltamos:

- A integração de ciência, trabalho, técnica, tecnologia, humanismo e cultura geral, possibilita o desenvolvimento tanto científico, como político e profissional dos indivíduos, pela não separação dessas dimensões no mundo real, estreitamente ligadas às condições basilares para o pleno exercício da cidadania;

- Os cursos técnicos integrados devem possibilitar a capacidade de formar o educando com uma educação básica sólida com vínculo estreito com a formação profissional, possibilitando assim uma formação integral, 
que contribua na integração social do aluno, que envolve o mundo do trabalho, ou seja:

[...] a oferta organizada se faz orientada a proporcionar a formação de cidadãos profissionais capazes de compreender a realidade social, econômica, política, cultural e do mundo do trabalho, para nela inserir-se e atuar de forma ética e competente, técnica e politicamente, visando à transformação da sociedade em função dos interesses sociais e coletivos especialmente os da classe trabalhadora (BRASIL, 2007, p. 35).

- a EJA, como um campo de conhecimento específico, deve procurar levá-la em consideração e investigar mais sobre o cenário e as necessidades efetivas dos alunos desse segmento, ou seja:

[...] como produzem/produziram os conhecimentos que portam, suas lógicas, estratégias e táticas de resolver situações e enfrentar desafios; como articular os conhecimentos prévios produzidos no seu estar no mundo àqueles disseminados pela cultura escolar; como interagir, como sujeitos de conhecimento, com os sujeitos professores, nessa relação de múltiplos aprendizados; de investigar, também, o papel do sujeito professor de EJA, suas práticas pedagógicas, seus modos próprios de reinventar a didática cotidiana, desafiando-o a novas buscas e conquistas - todos esses temas de fundamental importância na organização do trabalho pedagógico (BRASIL, 2007, p. 35 - 36).

- Ser um programa que busque de fato formular uma proposta político pedagógica com suas especificidades inerentes ao contexto da EJA, que possa atender às reais necessidades, buscando uma educação que tematize o campo da atuação profissional, o mundo do trabalho e a vida desses jovens e adultos;

- Um programa que permita enriquecer esses sujeitos mesmo que não garanta sua entrada no mundo do trabalho ou o alcance de outros objetivos, mas possibilite enriquecer seu leque de conhecimentos culturais, históricos, sociais e laborais, baseados nos ensinamentos freireanos de dar a possibilidade de ler o mundo, compreender tudo que o permeia;

- Formação de professores adequada ao campo específico de conhecimento, capaz de compreender as necessidades, as questões problemáticas desse universo, resultando em um profissional que investigue 
os modos de aprender de forma geral, para que possa compreender e também favorecer a aprendizagem desses alunos da EJA no ambiente escolar;

- Permitir que os professores e alunos possam e aprender uns com os outros, numa interação, envolvendo trocas de experiências de vida de cada indivíduo, ou seja:

[...] em fértil atividade cognitiva, afetiva, emocional, muitas vezes no esforço de retorno à escola, e em outros casos, no desafio de vencer estigmas e preconceitos pelos estudos interrompidos e a idade de retorno, é a perspectiva sensível com que a formação continuada de professores precisa lidar. Dessa forma, é fundamental que preceda à implantação dessa política uma sólida formação continuada dos docentes, por serem estes também sujeitos da educação de jovens e adultos, em processo de aprender por toda a vida (BRASIL, 2007, p. 36-37).

Dessa forma, O PROEJA permite uma formação humana, levando em consideração a formação para o mundo do trabalho, os conhecimentos científicos gerais necessários para a formação geral, além dos aspectos inerentes a questão da cidadania.

\section{A IMPLANTAÇÃO DO PROEJA NO CONTEXTO DO IFMA CAMPUS MARACANÃ: ouvindo a realidade}

O desenvolvimento da política educacional PROEJA acontece em diversos campi no contexto da cidade de São Luis-Maranhão, dentre eles, o Campus Maracanã, que oferece o ensino médio integrado ao curso técnico em agropecuária, levando em consideração o que determina o Regulamento Interno da instituição proponente, em plena consonância com o que está estabelecido pelo Documento Base Nacional (2007).

De acordo com o que está estabelecido pela proposta pedagógica do Proeja, Campus Maracanã (2010), o curso técnico em nível médio em agropecuária foi organizado buscando atender às condições sociais, econômicas e culturais da própria realidade em que a instituição se encontra inserida, considerando que o mundo globalizado vem colocando 
diversos desafios para a sociedade, de modo que a educação deve centrar-se na construção e reconstrução do conhecimento centrado na paz, na liberdade e na justiça social, utilizando-se de uma metodologia diversificada e também desafiadora.

Acreditamos que a educação profissional, aliada à formação geral e humana, desenvolve capacidades para a vida do cidadão como um todo, principalmente no que diz respeito à possibilidade de sua inserção no mundo do trabalho de forma significativa, compensando assim seu tempo perdido, tornando-o apto e qualificado para o engajamento profissional.

O texto a seguir, da LDB, corrobora com essa assertiva, ao explicitar que a educação profissional, integrada às diferentes formas de educação, ao trabalho, à ciência e à tecnologia, conduz ao permanente desenvolvimento de aptidões para a vida produtiva (BRASIL, 1996, Art. 39).

Como vemos, na LDB foi definida a importância de integrar a educação profissional a outras formações, visando à constituição de um conjunto de aptidões para o crescimento pessoal e profissional do próprio indivíduo. Na verdade, a LDB anunciou a possibilidade de se repensar a educação de jovens e adultos, garantindo-lhes uma formação ampla e conscientizadora, no sentindo de unificar educação geral, profissional e humana, para que haja uma intersecção entre elas e no desenvolvimento de abordagens e contribuições em todo o processo de formação do indivíduo. Sobre esse processo de intersecção entre as diversas formas de educação, o Documento Base (2007) ressalta:

Nessa intersecção, que compreende múltiplas dimensões, a qualificação nunca é apenas "profissional" (dimensão técnica), mas sempre "social" (dimensão sociolaboral). Pode-se falar, portanto, em qualificação social e profissional para denominar as ações de formação voltadas para uma inserção autônoma e solidária no mundo do trabalho. A qualificação social e profissional permite a inserção e atuação cidadã no mundo do trabalho, com efetivo impacto para a vida e o trabalho das pessoas (BRASIL, 2003, p. 24). Para isso, faz-se necessária no decorrer do processo formativo "a promoção de atividades político-pedagógicas" baseadas em metodologias inovadoras dentro de um pensamento emancipatório de inclusão, tendo o trabalho como princípio educativo; o direito ao trabalho como um valor estruturante da cidadania; a qualificação 
como uma política de inclusão social e um suporte indispensável do desenvolvimento sustentável, a associação entre a participação social e a pesquisa como elementos articulados na construção desta política e na melhoria da base de informação sobre a relação trabalho-educação-desenvolvimento (BRASIL, p. 46-47).

Observamos que a formação para o mundo do trabalho e para $\circ$ mundo da educação não devem ser consideradas e nem tratadas de modo dicotômicos na formação do indivíduo e, sim, condições necessárias. Não devem estar separadas no processo educacional, principalmente quando se trata do público da EJA, que já vem de um contexto sociocultural com sérios problemas educacionais e que precisa urgentemente de políticas reparadoras para minimizar os problemas que o afetam. Além disso, proporcionar aos discentes da EJA uma formação baseada em qualificação profissional e social e formação geral, aspectos esses fundamentais na formação do indivíduo, porquanto pautados na emancipação e autonomia para a construção e reconstrução da sua história de vida.

Para o ingresso no curso técnico em agropecuária - Proeja do Campus Maracanã, foi adotado como critério de avaliação a realização de um seletivo aberto a toda a comunidade no próprio Instituto, destinado aos jovens e adultos que concluíram o ensino fundamental e que ainda não haviam tido acesso ao ensino médio por alguma razão, para terem, assim, a oportunidade de concluí-lo. Foram oferecidas 40 vagas para o curso, as quais foram totalmente preenchidas.

Quanto ao tempo de duração e à sistemática de organização de sua carga horária, o curso conta com: uma carga horária de 3.160 horas, além do estágio, com disciplinas da formação geral e formação técnica, oferecidas no turno diurno, na forma presencial, seguindo o calendário escolar normal para todos os cursos de nível Técnico em ensino médio de acordo com o período letivo instituído pela instituição. A idade para ingresso no curso é de, no mínimo, 18 anos, de modo que há alunos com idade de até 60 anos, de acordo com a relação de matrícula. 
É importante salientar que a organização curricular do curso acontece de forma contínua, processual e coletiva, havendo assim a participação de todos no processo de elaboração e desenvolvimento, segundo a vivência de cada um. Sendo assim, essa organização se dá por meio dos princípios a seguir: inclusão da população em suas ofertas educacionais; inserção orgânica da modalidade EJA integrada à educação profissional nos sistemas educacionais públicos; ampliação do direito à educação básica, pela universalização do ensino médio; trabalho como principio educativo; pesquisa como fundamento da formação e condições geracionais, de gênero, das relações étnico-raciais como fundantes da formação humana e dos modos como se produzem as identidades sociais (IFMA, 2010 p. 07).

Esses princípios são orientadores do currículo, favorecendo à integralização dos saberes nos seus diversos aspectos social, político, humano, cultural, ambiental, ético, estético e profissional, os quais devem ser desenvolvidos através do eixo articulador: educação, trabalho e cidadania, abrangendo as dimensões técnico-científica, sociopolítica, metodológica e ético-cultural. Ainda nesse contexto de integralização dos saberes, existem também os eixos temáticos que dialogam diretamente com o eixo articulador. Os eixos temáticos são: identidade, diversidade e trabalho no campo; modos de trabalho, sistemas e processos agropecuários; organização social, cidadania, políticas públicas, meio ambiente, desenvolvimento sustentável e as tecnologias (IFMA, 2010 p. 07).

De modo que, essa integralização que ocorre entre os eixos tem como base a interdisciplinaridade, que desenvolve o diálogo entre os conhecimentos da formação profissional e das áreas da formação geral, permitindo a elevação da escolaridade.

Portanto, a proposta pedagógica explicita de forma precisa como se dá a integração dos saberes da formação profissional e da formação básica, como segue em anexo. 
A organização curricular instituída pela proposta pedagógica do Campus Maracanã buscou a articulação entre os conteúdos, conforme orienta o Programa, a fim de possibilitar uma formação ampla, constituindo desse modo o currículo integrado proposto para atender às necessidades dos jovens e adultos. O currículo é um dos aspectos primordiais para $O$ desenvolvimento da política do PA, por apresentar características singulares à realidade do público da EJA.

Desse modo, o curso técnico em agropecuária - PROEJA estruturouse em um plano com uma matriz curricular com a perspectiva de atingir as expectativas dos alunos, fazendo uma contextualização dos saberes com a realidade desses discentes, para garantir um conhecimento baseado em disciplinas de base científica e tecnológica que fazem parte do plano curricular do curso, além de oferecer disciplinas básicas que são necessárias para uma plena formação.

O PROEJA tem um papel fundamental na formação integral do indivíduo, através da elevação da escolaridade e da formação para o mundo do trabalho. Nesse sentido, faz-se necessário compreendermos como essa política teve seu processo de implantação no contexto do Instituto Federal do Maranhão Campus Maracanã, levando em consideração a percepção dos sujeitos envolvidos no processo.

Para o processo de coleta de dados empíricos nos embasamos em entrevistas semiestruturadas que foram gravadas, transcritas e, em seguida analisadas conforme a fundamentação teórica que abrange o objeto de pesquisa em estudo. As entrevistas foram realizadas com os sujeitos da pesquisa, em pleno exercício de suas atividades pedagógicas, sem intervir na sua rotina profissional.

O levantamento e apreciação dos dados se deu primeiramente pela visita realizada à instituição e, consequentemente, ao contato com as coordenadoras pedagógicas, participantes da pesquisa. Esse contato nos possibilitou o acesso ao plano do curso técnico em agropecuária (IFMA, 2010), por adotar O PROEJA, com vista a compreendermos a proposta 
pedagógica elaborada pelo IFMA, Campus Maracanã, em relação ao programa. Em seguida, entrevistamos as coordenadoras pedagógicas, com o objetivo de deter suas percepções sobre o processo de implantação do PROEJA no Contexto do Instituto Federal do Maranhão Campus Maracanã. E, por fim, ocorreu a organização e sistematização dos dados coletados, acompanhado de uma análise cuidadosa dos dados obtidos. Os sujeitos da pesquisa foram identificados por pseudônimos, substituímos seus verdadeiros nomes por nomes fictícios.

De acordo com o documento "Um novo modelo em educação profissional e tecnológica: concepções e diretrizes" (BRASIL, 2010 p.19) os institutos federais assumem 0 papel de agentes colaboradores na estruturação das políticas públicas para a região que polarizam, estabelecendo uma interação mais direta junto ao poder público e às comunidades locais.

Diante disso, cabe a cada instituição federal implantar e desenvolver políticas públicas como espaço fundamental para o desenvolvimento do seu trabalho e consequentemente proporcionar formação geral e profissional à comunidade.

Quando entrevistamos os sujeitos da pesquisa sobre porque a instituição resolveu implantar as turmas do PROEJA, assim se posicionaram os sujeitos:

Eu não acompanhei a implantação, o que eu sei é que dentro desse projeto de expansão do programa pelo governo federal, as instituições federais tiveram que se adequar a essa nova conjuntura e oferecer em seus campi o programa. É um programa que se expandiu de 2008 para cá e o instituto acompanhou esse processo (Coordenadora Cecilia).

Quando eu cheguei aqui no Instituto já estava implantado o Proeja, acho que eles implantaram o Proeja se eu não estiver enganada em 2007 ou na transição de 2007 para 2008. Eu cheguei em 2010, já encontrei turmas formadas do Proeja, então a gente só deu continuidade nesse acompanhamento [...] (Coordenadora Amanda).

Percebemos, com muita clareza, nas declarações das entrevistadas o desconhecimento sobre o porquê da instituição resolver implantar o 
PROEJA. Todavia é interessante ressaltarmos que as coordenadoras pesquisadas estão cientes de que o programa é uma política de cunho federal e que teria sido implantada desde 2007 e colocada em prática em 2008. Cabe ressaltarmos que, por mais que as Coordenadoras tivessem chegado depois da implantação do Programa no Instituto, ainda assim, teriam que buscar informações mais precisas acerca de sua importância social na formação cidadã do indivíduo, uma vez que elas deram continuidade ao processo de desenvolvimento do programa. Sobre isso, cabe destacar:

O papel que está previsto para os Institutos Federais é garantir a perenidade das ações que visem a incorporar, antes de tudo, setores sociais que historicamente foram alijados dos processos de desenvolvimento e modernização do Brasil, o que legitima e justifica a importância de sua natureza pública e afirma uma educação profissional e tecnológica como instrumento realmente vigoroso na construção e resgate da cidadania e da transformação social (BRASIL, 2010 p. 21).

Desse modo, é de extrema relevância que os institutos federais sejam de fato proponentes dessa política pública, possibilitando a sociedade uma formação profissional que transforme a condição socioeconômica existente.

Sobre essa mesma questão indagamos os professores. Vejamos as declarações de alguns professores sobre o porquê da implantação do PROEJA-Campus Maracanã:

"[...] quando eu cheguei já existia a política de Educação de Jovens e Adultos. Na minha visão é para você dar oportunidade, oportunizar pessoas que não tiveram esse momento [...] na sua cronologia de idade certa, para oportunizá-los para o mercado de trabalho, dar uma qualificação [...]" (Professor Ronald).

"[...] quando eu cheguei já existiam essas turmas, mas eu acho que foi tentando levar a educação a pessoas menos favorecidas, já com uma idade avançada" (Professora Jéssica).

"O PROEJA é uma meta do governo federal para a educação, para poder formar aquelas pessoas que não tiveram acesso à educação no tempo certo [...]" (Professora Juliana).

As declarações dos professores nos remetem ao fato da necessidade de proporcionar elevação da escolaridade e qualificação profissional a uma 
parcela da sociedade que se encontra fora do contexto educacional e que não usufrui do seu direito à educação. Diante disso, o governo federal, visando amenizar essa situação, desenvolveu a política do PROEJA para assistir de forma integral esses jovens e adultos.

Outros professores reafirmaram o que já foi expressado pelos seus pares dizendo o seguinte:

"[...] eu imagino que tenha sido por força de lei, uma exigência do MEC para que os Institutos Federais atuem na educação de jovens e adultos dentro da educação integral e educação profissionalizante" (Professor Felipe).

"[...] acredito que foi para atender às orientações e decisões do governo federal em implantar esse programa nas instituições federais de ensino, dando oportunidade de uma educação geral aliada a uma educação profissional para aqueles menos favorecidos da sociedade" (Professora Bianca).

Os professores enfatizaram bastante que a implantação do PROEJA pela instituição se deu por decisão do governo federal, e que todas as instituições federais teriam que oferecê-lo à sociedade, proporcionando aos jovens e adultos uma formação geral aliada à formação profissional. Conforme já expresso anteriormente por BRASIL (2007), uma política de natureza educacional direcionada à EJA tem que ter como princípio fundamental a elevação da escolaridade ligada ao processo de profissionalização, com a finalidade de contribuir para a integração sociolaboral dessa parcela da sociedade que se encontra em sua maioria limitada quanto ao direito à educação básica e ao acesso a uma formação profissional de qualidade. Porém na fala dos professores percebemos que o entendimento é muito mais para cumprir uma determinação legal, do que o resgate de um direito negado.

Defendemos que a educação voltada ao público da EJA deve ser pautada por uma formação integral que contemple formação básica e formação profissional, para que os discentes tenham a possibilidade de ser inseridos no mercado de trabalho e a partir disso sintam-se acolhidos pela 
sociedade de maneira igualitária e não desigual; que possam se sentir participantes do processo de transformação social, econômico e cultural.

Outro ponto interessante nos depoimentos diz respeito a como se deu a implantação do PROEJA. A esse respeito, as coordenadoras ressaltaram:

Essa eu não sei dizer como foi que se deu porque cheguei em 2010 e tinha saído a primeira turma. O que eu sei é que teve êxito, os alunos até hoje a gente tem encontro de egressos na escola, todos os alunos tão trabalhando na área então eu acho que foi um curso de sucesso. Agora a implantação mesmo eu não sei como foi (Coordenadora Cecília).

Como cheguei depois da implantação do Proeja não sei dá informações precisas acerca de como se deu essa implantação aqui no IFMA (Coordenadora Amanda).

As declarações das coordenadoras pedagógicas nos chama a atenção pelo desconhecimento do processo de implantação do PROEJA no IFMA, o que nos remete a pensarmos que as profissionais se apresentam alheias às informações importantes sobre essa política em relação ao contexto da Instituição. Faz-se necessário frisarmos que as coordenadoras pedagógicas desenvolvem suas atividades relacionadas ao programa, porém mais especificamente ao curso de agropecuária que adota o PROEJA. Sendo assim,

[...] os Institutos Federais assumem o papel de agentes colaboradores na estruturação das políticas públicas para a região que polarizam, estabelecendo uma interação mais direta junto ao poder público e às comunidades locais. Nesse sentido, cada Instituto Federal deverá dispor de um observatório de políticas públicas como espaço fundamental para o desenvolvimento do seu trabalho (BRASIL, 2010, p. 19).

Logo, ainda que as coordenadoras pedagógicas tivessem chegado no Instituto Federal do Maranhão campus Maracanã depois do processo de implantação do programa caberia a elas uma busca incessante por todos os documentos, informações e conhecimentos acerca da política e da instituição proponente. Só a partir disso, constituiriam um arcabouço teórico e uma lógica em suas declarações. 
Sobre o envolvimento da instituição na implantação do PROEJA, a equipe de professores relatou: "Essa resposta eu não tenho para the dar assim de forma precisa porque não me envolvi no planejamento, fui apenas convidada para ministrar uma disciplina" (Professora Jéssica).

"[...] a escola sempre trabalhou em cima da questão mesmo de resgatar a oportunidade de alguns alunos que estavam descartados da questão da educação, para implantar meios de fazer com que eles retornem às salas de aulas se aperfeiçoando" (Professor Pedro).

"[...] acredito que tenha sido da melhor maneira possível no intuito de atender o público da EJA de acordo com o que estava pré- estabelecido pela política" (Professora Bianca).

Portanto, o relato dos (as) professores (as) demonstrou que $50 \%$ do corpo docente não estiveram presentes e nem se envolveram no processo de implantação do PROEJA na instituição, pelo fato de terem chegado após o início das atividades deste e por terem sido apenas convidados para ministrar determinada disciplina no programa. Por outro lado, os outros $50 \%$ dos docentes expressaram que esse envolvimento por parte da instituição ocorreu pela necessidade de proporcionar Educação aos Jovens e Adultos, trazendo-os para o contexto da sala de aula, resgatando-os para um convívio socioeducativo. Assim, a instituição não mediu esforços para oportunizar a sociedade esse direito no seu sentido amplo, isto é, sem restrições de idade, raça e local de moradia, pois todos tiveram acesso ao Programa.

Ainda no que diz respeito ao envolvimento dos professores na implantação do PROEJA, os docentes participantes da pesquisa assim se posicionaram:

"Eu participei de uma reunião com a coordenação do Proeja local, esclareceram quem eram os alunos, como eles deveriam ser abordados e quais seriam os nossos objetivos a serem colocados na disciplina [...]" (Professora Jéssica).

"[...] fiz no instituto um curso de especialização na área de Educação de Jovens e Adultos" (Professora Juliana). 
"[...] quando cheguei aqui e comecei a ministrar aulas aos alunos do Proeja, tentei adequar a minha metodologia de acordo com o perfil dos alunos da EJA [...]" (Professora Bianca).

No depoimento dos professores, observamos como ocorreu a participação deles no processo de implantação do Programa; cada um expressou sua visão, sua forma de olhar a política da EJA, o que nos leva a compreender a heterogeneidade apresentada em relação à forma como esses docentes absorveram a implantação do Programa.

Outros docentes, por sua vez, apontaram questões primordiais, como: a oportunidade que seria dada aos jovens e adultos, a metodologia que deveria ser utilizada para trabalhar com a EJA, a participação dos professores em um curso de especialização e a afinidade que existe em relação aos alunos do PROEJA. As afirmações dos professores a respeito tanto do seu envolvimento quanto da instituição evidenciam aspectos importantes, como, por exemplo, a preparação da equipe gestora e docente para o desenvolvimento do Programa, de acordo com as necessidades do público da EJA e suas especificidades, uma vez que historicamente esses sujeitos são considerados "marginais", por se encontrarem em situação de vulnerabilidade social, pela baixa escolaridade e também pelo fato de estarem à margem das políticas educacionais.

A EJA, em síntese, trabalha com sujeitos marginais ao sistema, com atributos sempre acentuados em consequência de alguns fatores adicionais como raça/ etnia, cor, gênero, entre outros. Negros, quilombolas, mulheres, indígenas, camponeses, ribeirinhos, pescadores, jovens, idosos, subempregados, desempregados, trabalhadores informais são emblemáticos representantes das múltiplas apartações que a sociedade brasileira, excludente, promove para grande parte da população desfavorecida econômica, social e culturalmente (BRASIL, 2007, p.6).

Para isso, é relevante que ocorra o desenvolvimento de uma prática pedagógica que considere essa realidade e o perfil de aluno, portanto, fazse necessário que haja primeiramente uma formação que favoreça ao docente uma atuação assentada na reflexão sobre sua prática, levando-o a buscar alternativas para um melhor desenvolvimento da ação educativa. 
Reiteramos que, segundo Freire (1996), a prática educativa deve ser pensada e repensada de maneira crítica e reflexiva para melhor desempenhá-la. Desse modo, para o contexto da EJA, especificamente o PROEJA requer essa ação crítica e reflexiva, para que os profissionais estejam preparados para lidar com esse público, principalmente no que diz respeito ao seu contexto de vida.

\section{CONSIDERAÇÕES FINAIS}

Como podemos constatar, a política do PROEJA representa um caminho de conquistas na vida educacional e profissional de uma parcela significativa da sociedade, que são os jovens e adultos. São eles que precisam ser assistidos por políticas públicas de caráter educacional que contemple uma formação completa, fazendo com que esse público se integre e sinta-se na sua totalidade sujeito do processo de desenvolvimento de uma política em todo o seu aspecto. Até porque são sujeitos que em muitos casos se encontram em uma situação de vulnerabilidade, que estão fora do contexto educacional e que nem concluíram o ensino fundamental.

Desse modo, como pesquisadoras envolvidas diretamente no campo da pesquisa, movidas pela natureza investigativa, na busca de respostas que venham possibilitar uma maior compreensão acerca do objeto em estudo, entendemos que o conhecimento se encontra em um constante processo de transformação que necessita ser sempre analisado, investigado e abarcado na sua intensidade, para que alcancemos um entendimento seguro e então possamos obter as respostas de que necessitamos.

A pesquisa empírica nos proporcionou um contato próximo com o objeto pesquisado, por meio do fenômeno investigado, ao entrevistarmos as coordenadoras e os professores do curso de agropecuária - PROEJA, a fim de captarmos as percepções dos mesmos sobre o processo de implantação pedagógica do Proeja no instituto Federal de Educação, Ciência e Tecnologia do Maranhão Campus Maracanã. 
O PROEJA tem significado na construção de uma educação mais humana, proporcionando oportunidades ao jovem e ao adulto de alcançar uma qualificação para que consiga sua inserção no mundo do trabalho, além do processo socialização entre todos que estão ligados direta ou indiretamente ao programa, que é também um aspecto fundamental para reintegração desse jovem na sociedade.

Porém, faz-se necessário ressaltarmos o quanto seria importante que as instituições proponentes do programa seguissem de forma precisa o que está estabelecido pelo Documento Base Nacional do Proeja, pois somos cientes da organização dessa política, principalmente no que diz respeito ao aspecto pedagógico, em que oferece um conjunto de caminhos a serem percorridos sempre buscando o alcance da formação geral aliada a formação profissional, como bem colocado pela política. Apesar dos entraves que levam com que as políticas não sejam executadas de maneira responsável para com os que dela dependem diretamente.

Deste modo, reafirmamos o quanto é necessário a produção e o desenvolvimento de políticas de cunho educacional para oportunizar a sociedade como um todo, principalmente quando a política busca amenizar as questões de socioculturais de uma parcela da sociedade que na maioria das vezes se encontra à margem do processo.

\section{REFERÊNCIAS}

BRASIL. Projeto do Programa PROJOVEM. Programa Nacional de Inclusão de Jovens. Educação, Qualificação e Ação Comunitária. Presidência da República. Secretaria Nacional de Inclusão de Jovens. Brasília: 2005.

BRASIL. PROEJA: Programa Nacional de Integração da Educação Profissional com a Educação Básica na Modalidade de Educação de Jovens e Adultos. Brasilia, 2007.

BRASIL. Um novo modelo em educação profissional e tecnológica: concepções e diretrizes. Instituto Federal de Educação, ciência e tecnologia. 2010.

FREIRE, P. Pedagogia da Autonomia: saberes necessários à prática educativa. Rio de Janeiro: Paz e Terra, 1996. 
INSTITUTO FEDERAL DE EDUCAÇÃO, CIÊNCIA E TECNOLÓGIA (IFMA) CAMPUS MARACANÃ. Plano de Curso Agropecuária - PROEJA. Eixo Tecnológico: recursos naturais. São Luís - MA. 2010.

PAIVA, V. P. Educação popular e educação de jovens e adultos. Rio de Janeiro: Edições Loyola, 1973.

PAIVA, V. P. Educação popular e educação de adultos. São Paulo: Edições Loyola, 1987.

Recebido em: Outubro de 2016 Aceito em: Dezembro de 2016 